\title{
Effects of RF Power and Treatment Time on Wettability of Oxygen Plasma-Treated Diamond-like Carbon Thin Films
}

\author{
C. Jongwannasiri and S. Watanabe
}

\begin{abstract}
Diamond-like carbon (DLC) thin films can be used in numerous industrial applications, including biomedical modified-surfaces with biocompatible and wetting properties. It is important to understand the surface properties of DLC thin films for these applications. In this study, oxygen $\left(\mathrm{O}_{2}\right)$ plasma treatment on DLC film surfaces is studied, taking into account the effects of radio frequency (RF) power and treatment time on wetting property. All the films were prepared on $\mathrm{Si}(100)$ wafers using a plasma-based ion implantation (PBII) technique using acetylene $\left(\mathrm{C}_{2} \mathrm{H}_{2}\right)$ as the plasma source. The deposited DLC films were then treated with oxygen plasma using various $R F$ powers and treatment times in order to characterize the wettability, compared to as-deposited DLC film. The thickness and structure of the films were evaluated using stylus profilometer and Raman spectroscopy. The wettability of the films was assessed using a contact angle meter. The results indicate the oxygen plasma treatment on DLC film surfaces influenced to thickness change, but unaffected to structure of the films with various RF powers and treatment times. Further, oxygen plasma-treated DLC films exhibit a hydrophilic surface due to the introduction of some hydroxyl and carbonyl groups onto the DLC film surface. It is concluded that oxygen plasma treatment can be used to make hydrophilic DLC, making it a favorable wetting surface for biomedical applications.
\end{abstract}

Index Terms-Diamond-like carbon, surface modification, plasma treatment, wettability.

\section{INTRODUCTION}

Diamond-like carbon (DLC) films have been intensively studied in the past due to their excellent characteristics such as chemical inertness, high hardness, low friction coefficient, wear resistance, and biocompatibility [1], [2]. Recent studies have reported that surface-modified DLC films improved biocompatibility, lubricity, stability, and cell adhesion [3]-[6]. These characteristics are related to surface roughness [7], [8], structural bonds [9], [10], and whether the film is hydrophilic or hydrophobic [11], [12]. The DLC surface modification was performed by doping with suitable elements [4]-[6], [13] and plasma treatment [14], [15]. Owing to the chemically active species in plasma and ease of processing, plasma treatment is the most widely used method for surface modification. Recently, oxygen plasma treatment has become a technique widely used on both experimental and industrial

Manuscript received August 26, 2013; revised October 30, 2013.

C. Jongwannasiri is with the Graduate school at Nippon Institute of Technology, Saitama, 345-8501 Japan (e-mail: s3124601@sstu.nit.ac.jp, chavin.jon@outlook.co.th).

S. Watanabe is with the Department of Innovative Systems Engineering, Nippon Institute of Technology, Saitama, 345-8501 Japan (e-mail: shwata@nit.ac.jp). scales; for instance, Santos et al. found that oxygen plasma treatment enhances the surface energy of DLC films which may further improve their surface hardness [16]. In addition, Choi et al. also devoted their enthusiastic attention towards oxygen plasma in DLC films to improve their tribological properties [17]. The improvement of the surface energy and friction coefficient of DLC is a direct consequence of the surface activation processes required for many technological applications including its use as a biomaterial [15], [18], [19]. In the view of all these, oxygen plasma treatment on DLC film surfaces may provide a new efficient approach to improve the mechanical, tribological and biological properties of the films without a need of any complex hybrid system geometry. So there is great scope to work on this topic further.

In this study, DLC films were synthesized by a plasma-based ion implantation (PBII) technique using acetylene $\left(\mathrm{C}_{2} \mathrm{H}_{2}\right)$ as the plasma source. The as-deposited DLC films were then treated with oxygen $\left(\mathrm{O}_{2}\right)$ plasma using various radio frequency $(\mathrm{RF})$ powers and treatment times in order to characterize the wettability of DLC films after plasma treatment when compared to as-deposited DLC film. The film properties were evaluated by stylus profilometer, Raman spectroscopy, and contact angle measurement.

\section{MATERIALS AND METHODS}

A schematic of the PBII system used for the deposition and plasma treatment of DLC films on a silicon wafer is shown in Fig. 1. Si (100) wafers measuring $0.7 \mathrm{~mm}$ in thickness were used as a substrate. The wafers were sputter cleaned with $\mathrm{Ar}^{+}$ for $20 \mathrm{~min}$ to remove residual surface contaminants and surface oxides using a negative-pulsed bias voltage of $10 \mathrm{kV}$. Using a negative-pulsed bias voltage of $20 \mathrm{kV}$, the DLC film interlayer was first deposited with $\mathrm{CH}_{4}$ for $60 \mathrm{~min}$ to improve adhesion between the film and substrate. The deposition of the DLC films was performed at a negative-pulsed bias voltage of $5 \mathrm{kV}$ with $\mathrm{C}_{2} \mathrm{H}_{2}$ for $150 \mathrm{~min}$. A pulse width of $5 \mu \mathrm{s}$, a pulse delay of $25 \mu \mathrm{s}$, and a pulse frequency of $1 \mathrm{kHz}$ were utilized during the coating process. The deposition pressure was set to $2 \mathrm{~Pa}$. After deposition, oxygen plasma was treated in the chamber with the various RF powers at 100,300 , and $500 \mathrm{~W}$ for 5,10 , and $15 \mathrm{~min}$. The plasma treatment pressure was also set to $2 \mathrm{~Pa}$.

The film properties were studied using several characterization techniques. The thickness of the films was measured by stylus profilometer. For each surface, at least five times were measured. The structure of the films was 
analyzed using Raman spectroscopy (JASCO NRS-1000 DT) at an excitation wavelength of $532 \mathrm{~nm}$, and a spot size of $4 \mu \mathrm{m}$ The Raman spectra in the wave number region were deconvoluted from $1000-1800 \mathrm{~cm}^{-1}$ into the Gaussian D and $G$ peaks. The integral area under the $D$ and $G$ peaks was determined by curve fitting. The contact angle $(\theta)$ was measured under atmospheric conditions at room temperature with a contact angle meter (Kyowa Interface Science Co., Ltd.) using distilled water, diiodomethane, and ethylene glycol as the tested liquids. A droplet of the tested liquids with a volume of $1 \mu \mathrm{L}$ was released onto the surface of a sample. For each surface, at least five droplets were measured. The surface energy of the sample was calculated based on the measured contact angles using the extended Fowkes theory according to Kitazaki and Hata [21], [22].

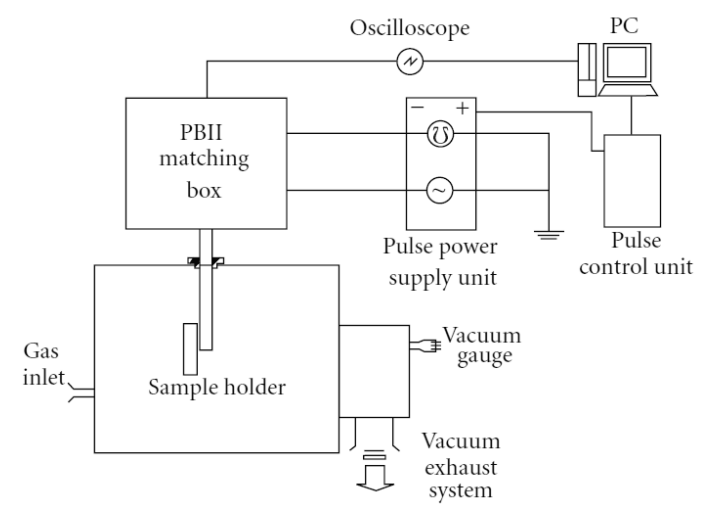

Fig. 1. A schematic of the PBII apparatus used in this experiment [20].

\section{RESULTS AND DISCUSSION}

The thickness change in DLC films after oxygen plasma treatment at different RF powers (100, 300 and $500 \mathrm{~W})$ and treatment times $(5,10$ and $15 \mathrm{~min})$ is shown in Fig. 2. The erosion depth when treated at different RF powers increases in accordance with an increase in treatment time, except for those films treated at the RF power of $500 \mathrm{~W}$ for $15 \mathrm{~min}$. In fact, the increase of RF power and treatment time resulted in an increase of ion energy, leading to a higher erosion rate. This phenomenon may occur due to both the higher RF power and treatment time, reducing the erosion depth. According to Choi et al., the higher RF power produces a larger plasma sheath region [23], indicating a reduction in erosion depth, i.e. the ion bombardment decreases in accordance with a larger plasma sheath, resulting in decreasing of erosion rate. Further, the reason why the film thickness treated at the RF power of $500 \mathrm{~W}$ for $10 \mathrm{~min}$ is larger than that of $300 \mathrm{~W}$ is the same as mentioned above. Therefore, it is concluded that the thickness change in DLC films was affected using oxygen plasma treatment using various RF powers and treatment times.

The Raman spectra of the DLC and oxygen plasma-treated DLC films are shown in Fig. 3. The position of the $\mathrm{G}$ peak is related to the bond-angle disorder or the $\mathrm{sp}^{3}$ bonding content, while the $\mathrm{I}_{\mathrm{D}} / \mathrm{I}_{\mathrm{G}}$ ratio is proportional to the ratio of $\mathrm{sp}^{2} / \mathrm{sp}^{3}$ [24], [25]. These two factors play a major role in assessing the Raman spectra. In particular, the ratio of $\mathrm{sp}^{2} / \mathrm{sp}^{3}$ is one of the most important factors governing the quality of DLC films. Generally, the likelihood that the properties of DLC films will resemble those of a diamond increases when this ratio is low. The as-deposited DLC and oxygen plasma-treated DLC films fabricated in this experiment exhibit a broad spectrum composed of a D peak $\left(1350 \mathrm{~cm}^{-1}\right)$ and a $\mathrm{G}$ peak $\left(1580 \mathrm{~cm}^{-1}\right)$, which are similar to the peaks observed in conventional DLC films. As shown in Fig. 3, the shape of the Raman spectra did not change in the oxygen plasma-treated DLC films using the various RF powers and treatment times when compared to as-deposited DLC. All the spectra show typical diamond-like structures with a broad $\mathrm{G}$ peak among $1533-1535 \mathrm{~cm}^{-1}$, and $\mathrm{I}_{\mathrm{D}} / \mathrm{I}_{\mathrm{G}}$ ratio in the range of $0.61-0.64$. These results indicate that the structure of the films was relatively unaffected using oxygen plasma treatment using various RF powers and treatment times.

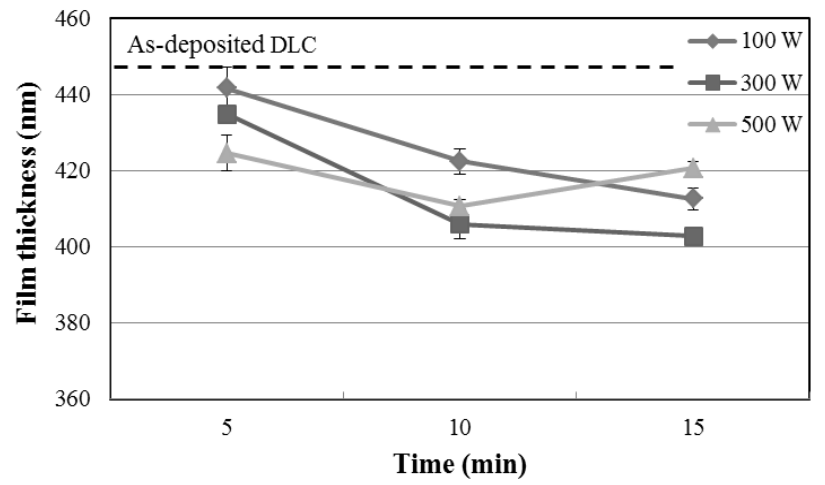

Fig. 2. Effects of RF powers and plasma treatment times on the thickness of DLC films.

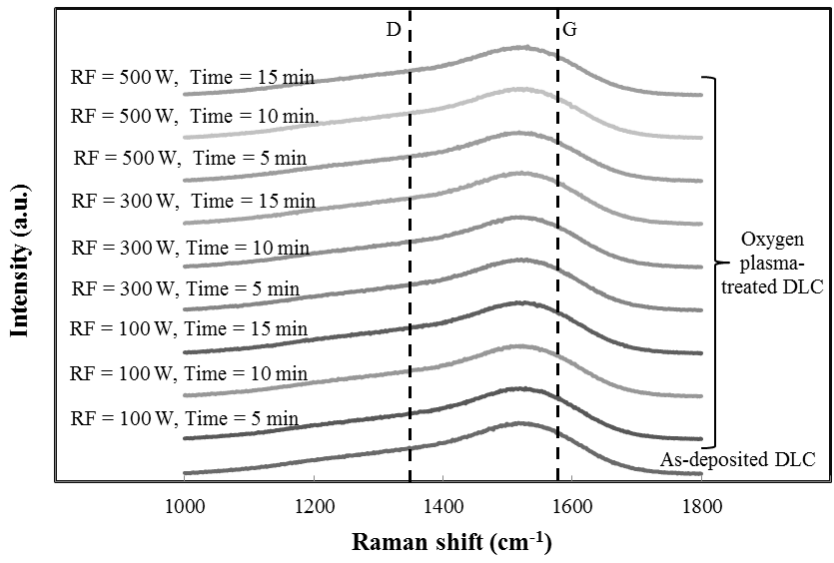

Fig. 3. Raman spectra of the DLC and oxygen plasma-treated DLC films using the various RF powers and treatment times.

Contact angle and surface energy have great potential utility. They can characterize and predict the wettability of materials. The contact angle and surface energy results of DLC and oxygen plasma-treated DLC films are shown in Table I. DLC film tends to be a hydrophobic surface with a water contact angle of approximately $75^{\circ}$, while the oxygen plasma-treated DLC films tend to be hydrophilic surfaces with a water contact angle of approximately $39^{\circ}-49^{\circ}$. The water contact angles for all oxygen plasma-treated DLC film surfaces were lower than that of an untreated DLC film surface, indicating that a hydrophilic DLC can be obtained by oxygen plasma treatment. Further, the total surface energy also increased $(46.2 \mathrm{mN} / \mathrm{m}$ to $87.1 \mathrm{mN} / \mathrm{m})$ as the oxygen plasma treatment on DLC film surfaces. The total surface energy $\left(\gamma^{\mathrm{T}}\right)$ of the films is estimated as the sum of the 
dispersion component $\left(\gamma^{\mathrm{d}}\right)$, the polar component $\left(\gamma^{\mathrm{p}}\right)$, and the hydrogen-bonding component $\left(\gamma^{\mathrm{h}}\right)$. According to Yin et al., oxygen plasma produces energetic oxygen species which can bond easily to the DLC film surfaces [26]. This can increase the concentration of carbon-oxygen structures on the DLC film surfaces, resulting in the addition of a hydrophilic property, contributing to the adsorption hysteresis related to high surface energy [26], [27]. The adsorption of oxygen on a DLC film surface forms oxygen incorporated functional groups since oxygen can occupy the bridge site on the surface [28]. Additionally, the interaction of oxygen with $\mathrm{C}-\mathrm{H}$ bonds results in $\mathrm{C}-\mathrm{OH}$ bonds. The $\mathrm{C}-\mathrm{O}$ and $\mathrm{C}-\mathrm{OH}$ polar bonds make the surface more reactive and increase dipole-dipole interactions between polar molecules and the film surface. Therefore, it is concluded that the increasing surface energy was largely ascribed to the increase in the polar $(3.3 \mathrm{mN} / \mathrm{m}$ to $41.2 \mathrm{mN} / \mathrm{m})$ and hydrogen-bonding $(2.1 \mathrm{mN} / \mathrm{m}$ to $21.8 \mathrm{mN} / \mathrm{m})$ components. The polar component is controlled by several intermolecular forces, permanent and induced dipoles, and hydrogen bonds [18], [29]. The hydrogen bonding force is an indicator of the ability to form hydrogen bonds at the surface. The wettability, that is, hydrophobic or hydrophilic, is also related to hydrogen bonding at the surface [30].

As mentioned above, the oxygen plasma treatment was able to introduce some of the hydroxyl groups $(-\mathrm{OH})$ onto the DLC film surface. As the plasma treatment power becomes higher, oxidation occurs and some of the hydroxyl groups might be transformed into the carbonyl groups $(\mathrm{C}=\mathrm{O})$, which are known to contribute less to hydrophilicity than the hydroxyl groups [31]. This could be a reason why the oxygen plasma treatment should be treated at the lower power which exhibits a higher hydrophilic property. In this experiment, the best hydrophilic surface occurred at the RF power of $500 \mathrm{~W}$, with the plasma treatment time of $15 \mathrm{~min}$. This phenomenon may occur due to both the higher RF power and treatment time, which can induce the roughened surface. According to Wenzel's law, the contact angle decreases, indicating the hydrophilic property as the surface becomes roughened [32]. It can be clearly seen from Table I that there are a few different values of surface energy among the RF powers of 100,300 , and $500 \mathrm{~W}$ at the highest treatment time (15 min). However, the surface energy at the RF power of $100 \mathrm{~W}$, with the lower treatment time (5 and $10 \mathrm{~min}$ ) is better than the higher RF powers ( $300 \mathrm{~W}$ and $500 \mathrm{~W}$ ) when compared to the same treatment times. Therefore, a greater increase in the values of $\gamma^{\mathrm{p}}$ and $\gamma^{\mathrm{h}}$ is responsible for the enhanced wettability because of the strong dipole-dipole and hydrogen-bonding interaction at the interfaces. The oxygen plasma-treated DLC film is thus hydrophilic, making it a favorable wetting surface for biological and biomedical applications.

TABLE I: CONTACT ANGLE AND SURFACE ENERGY OF AS-DEPOSITED DLC COMPARED TO OXYGEN PLASMA-TREATED DLC

\begin{tabular}{|c|c|c|c|c|c|c|c|c|c|}
\hline \multirow{2}{*}{ Sample } & \multirow{2}{*}{$\begin{array}{l}\text { RF Power } \\
\text { (W) }\end{array}$} & \multirow{2}{*}{$\begin{array}{l}\text { Treatment } \\
\text { Time (min) }\end{array}$} & \multicolumn{3}{|c|}{ Contact angle $\left(^{\circ}\right)$} & \multicolumn{4}{|c|}{ Surface energy (mN/m) } \\
\hline & & & Distilled water & Diiodomethane & Ethylene glycol & $\gamma^{\mathrm{d}}$ & $\gamma^{\mathrm{p}}$ & $\gamma^{\mathrm{h}}$ & $\gamma^{\mathrm{T}}$ \\
\hline $\begin{array}{l}\text { As-deposited } \\
\text { DLC }\end{array}$ & - & - & $74.8 \pm 0.4$ & $30.3 \pm 0.8$ & $43.7 \pm 0.4$ & 40.8 & 3.3 & 2.1 & 46.2 \\
\hline \multirow{8}{*}{$\begin{array}{l}\text { Oxygen } \\
\text { plasma-treated } \\
\text { DLC }\end{array}$} & 100 & 5 & $46.1 \pm 0.6$ & $33.5 \pm 0.4$ & $21.7 \pm 0.2$ & 26.8 & 31.3 & 17.6 & 75.7 \\
\hline & 100 & 10 & $41.1 \pm 0.5$ & $33.0 \pm 0.5$ & $17.9 \pm 0.4$ & 24.9 & 39.4 & 20.9 & 85.2 \\
\hline & 100 & 15 & $41.3 \pm 0.5$ & $33.5 \pm 0.4$ & $17.3 \pm 0.6$ & 25.1 & 37.9 & 20.8 & 83.8 \\
\hline & 300 & 5 & $48.5 \pm 0.5$ & $35.6 \pm 0.4$ & $20.2 \pm 0.3$ & 28.5 & 22.7 & 16.3 & 67.5 \\
\hline & 300 & 10 & $46.0 \pm 0.6$ & $35.7 \pm 0.3$ & $20.4 \pm 0.1$ & 26.7 & 28.6 & 18.1 & 73.4 \\
\hline & 300 & 15 & $40.1 \pm 0.7$ & $34.5 \pm 0.3$ & $15.3 \pm 0.3$ & 24.7 & 38.0 & 21.8 & 84.5 \\
\hline & 500 & 5 & $48.1 \pm 0.6$ & $31.9 \pm 0.4$ & $22.4 \pm 0.2$ & 28.2 & 28.2 & 15.9 & 72.3 \\
\hline & 500 & 15 & $40.5 \pm 0.6$ & $31.9 \pm 0.4$ & $17.5 \pm 0.4$ & 24.9 & 41.2 & 21.0 & 87.1 \\
\hline
\end{tabular}

$\gamma^{\mathrm{d}}$ : dispersion force component, $\gamma^{\mathrm{p}}$ : polar force component, $\gamma^{\mathrm{h}}$ : hydrogen-bonding force component, $\gamma^{\mathrm{T}}$ : total surface energy

\section{CONCLUSION}

The oxygen plasma treatment on DLC film surfaces was successfully synthesized on Si (100) wafers using the PBII technique. The films were investigated for the effects of RF power and treatment time on the wettability using stylus profilometer, Raman spectroscopy, and contact angle measurement. The oxygen plasma treatment using various RF powers and treatment times influenced to thickness change due to oxygen plasma erosion on the DLC film surfaces. However, the shape of the Raman spectra did not change for the oxygen plasma-treated DLC films using the various RF powers and treatment times when compared to as-deposited DLC. It indicates the structure of the films was relatively unaffected using the oxygen plasma treatment. Further, the oxygen plasma treatment on DLC films exhibits a hydrophilic surface due to the introduction of some hydroxyl and carbonyl groups onto the DLC film surface. Based on the aforementioned results, oxygen plasma treatment can be used to make hydrophilic DLC, making it a favorable wetting surface for biomedical applications. For further studies, the biological experiments should be performed for assessing the biocompatibility on hydrophilic DLC film surfaces, compare to as-deposited DLC film.

\section{REFERENCES}

[1] J. Robertson, "Diamond-like amorphous carbon," Mater. Sci. Eng., R, vol. 37, pp. 129-281, May 2002. 
[2] L. F. Bonetti, G. Capote, L. V. Santos, E. J. Corat, and V. J. T. Airoldi, "Adhesion studies of diamond-like carbon films deposited on Ti6Al4V substrate with a silicon interlayer," Thin Solid Films, vol. 515, pp. 375-379, Sep. 2006.

[3] E. T. Uzumaki, C. S. Lambert, A. R. Santos, and C. A. C. Zavaglia, "Surface properties and cell behaviour of diamond-like carbon coatings produced by plasma immersion," Thin Solid Films, vol. 515, pp 293-300, Sep. 2006.

[4] S. Zhang, H. Du, S.-E. Ong, K.-N. Aung, H.-C. Too, and X. Miao, "Bonding structure and haemocompatibility of silicon-incorporated amorphous carbon," Thin Solid Films, vol. 515, pp. 66-72, Sep. 2006.

[5] R. Hauert, "A review of modified DLC coatings for biological applications," Diamond Relat. Mater., vol. 12, pp. 583-589, Mar.-Jul. 2003.

[6] T. Nakamura, T. Ohana, M. Suzuki, M. Ishihara, A. Tanaka, and Y. Koga, "Surface modification of diamond-like carbon films with perfluorooctyl functionalities and their surface properties," Surf. Sci. vol. 580, pp. 101-106, Apr. 2005.

[7] W. J. Ma, A. J. Ruys, R. S. Mason, P. J. Martin, A. Bendavid, Z. Liu, M. Ionescu, and $\mathrm{H}$. Zreiqat, "DLC coatings: Effects of physical and chemical properties on biological response," Biomaterials, vol. 28, pp. 1620-1628, Mar. 2007

[8] J. A. McLaughlin, B. Meenan, P. Maguire, and N. Jamieson, "Properties of diamond like carbon thin film coatings on stainless steel medical guidewires," Diamond Relat. Mater., vol. 5, pp. 486-491, Apr. 1996.

[9] J. Y. Chen, L. P. Wang, K. Y. Fu, N. Huang, Y. Leng, Y. X. Leng, P. Yang, J. Wang, G. J. Wan, H. Sun, X. B. Tian, and P. K. Chu, "Blood compatibility and $\mathrm{sp}^{3} / \mathrm{sp}^{2}$ contents of diamond-like carbon (DLC) synthesized by plasma immersion ion implantation-deposition," Surf. Coat. Technol., vol. 156, pp. 289-294, Jul. 2002.

[10] Q. Zhao, Y. Liu, C. Wang, and S. Wang, "Bacterial adhesion on silicon-doped diamond-like carbon films," Diamond Relat. Mater., vol. 16, pp. 1682-1687, Aug. 2007.

[11] T. Yokota, T. Terai, T. Kobayashi, T. Meguro, and M. Iwaki, "Cell adhesion to nitrogen-doped DLCs fabricated by plasma-based ion implantation and deposition method using toluene gas," Surf. Coat. Technol., vol. 201, pp. 8048-8051, Aug. 2007.

[12] A. Rich and A. K. Harris, "Anomalous preferences of cultured macrophages for hydrophobic and roughened substrata," J. Cell Sci. vol. 50, pp. 1-7, Aug. 1981

[13] T. I. T. Okpalugo, A. A. Ogwu, P. D. Maguire, and J. A. D. McLaughlin, "Platelet adhesion on silicon modified hydrogenated amorphous carbon films," Biomaterials, vol. 25, pp. 239-245, Jan. 2004.

[14] S.-W. Ha, R. Hauert, K.-H. Ernst, and E. Wintermantel, "Surface analysis of chemically-etched and plasma-treated polyetheretherketone (PEEK) for biomedical applications," Surf. Coat. Technol., vol. 96, pp. 293-299, Nov. 1997.

[15] R. K. Roy, H.-W. Choi, S.-J. Park, and K.-R. Lee, "Surface energy of the plasma treated $\mathrm{Si}$ incorporated diamond-like carbon films," Diamond Relat. Mater., vol. 16, pp. 1732-1738, Sep. 2007.

[16] C. L. Santos, F. Yubero, J. Cotrino, and A. R. G. Elipe, "Lateral and in-depth distribution of functional groups on diamond-like carbon after oxygen plasma treatments," Diamond Relat. Mater., vol. 20, pp. 49-56, Feb. 2011.

[17] J. Choi, S. Nakao, M. Ileyama, and T. Kato, "Effect of oxygen plasma treatment on the tribological properties of Si-DLC coatings," Phys. Status Solidi, vol. 5, pp. 956-959, Apr. 2008.

[18] R. K. Roy, H. W. Choi, J. W. Yi, M.-W. Moon, K.-R. Lee, D. K. Han, J. H. Shin, A. Kamijo, and T. Hasabe, "Hemocompatibility of surface-modified, silicon-incorporated, diamond-like carbon films," Acta Biomater., vol. 5, pp. 249-256, Jan. 2009.

[19] M. Anil, S. F. Ahmed, J. W. Yi, M.-W. Moon, K.-R. Lee, Y. C. Kim, H. K. Seok, and S. H. Han, "Tribological performance of hydrophilic diamond-like carbon coatings on Ti-6Al-4V in biological environment," Diamond Relat. Mater., vol. 19, pp. 300-304, Apr. 2010.

[20] C. Jongwannasiri, N. Moolsradoo, A. Khantachawana, P. Kaewtatip, and S. Watanabe, "The Comparison of Biocompatibility Properties between Ti Alloys and Fluorinated Diamond-Like Carbon Films,"
Advances in Materials Science and Engineering, vol. 2012, pp. 1-8, Feb. 2012

[21] Y. Kitazaki and T. Hata, "Surface-chemical criteria for optimum adhesion," J. Adhes., vol. 4, pp. 123-132, 1972.

[22] T. Hata, Y. Kitazaki, and T. Saito, "Estimation of the surface energy of polymer solids," J. Adhes., vol. 21, pp. 177-194, 1987.

[23] W. S. Choi, J. Heo, I. Chung, and B. Hong, "The effect of RF power on tribological properties of the diamond-like carbon films," Thin Solid Films, vol. 475, pp. 287-290, Mar. 2005.

[24] M. A. Capano, N. T. McDevitt, R. K. Singh, and F. Qian, "Characterization of amorphous carbon thin films," J. Vac. Sci. Technol., A, vol. 14, pp. 431-435, Mar. 1996.

[25] J. Qi, J. B. Luo, S. Z. Wen, J. Wang, and W. Z. Li, "Mechanical and tribological properties of non-hydrogenated DLC films synthesized by IBAD," Surf. Coat. Technol., vol. 128-129, pp. 324-328, Jun. 2000.

[26] Y. Yin, L. Hang, J. Xu, D. R. McKenzie, and M. M. M. Bilek, "Surface adsorption and wetting properties of amorphous diamond-like carbon thin films for biomedical applications," Thin Solid Films, vol. 516, pp. 5157-5161, Jun. 2008.

[27] S. Meskinis, S. Tamulevicius, V. Kopustinskas, M. Andrulevicius, A Guobiene, R. Gudaitis, and I. Liutviniene, "Hydrophobic properties of the ion beam deposited DLC films containing $\mathrm{SiO}_{\mathrm{x}}$," Thin Solid Films, vol. 515, pp. 7615-7618, Jul. 2007.

[28] Y. M. Wang, K. W. Wong, S. T. Lee, M. N. Gamo, K. P. Loh, and T. Ando, "Recent studies on diamond surfaces," Diamond Relat. Mater., vol. 9, pp. 1582-1590, Sep.-Oct. 2000.

[29] A. Bendavid, P. J. Martin, L. Randeniya, and M. S. Amin, "The properties of fluorine containing diamond-like carbon films prepared by plasma-enhanced chemical vapour deposition," Diamond Relat. Mater., vol. 18, pp. 66-71, Jan. 2009.

[30] N. Moolsradoo and S. Watanabe, "Modification of tribological performance of DLC films by means of some elements addition," Diamond Relat. Mater., vol. 19, pp. 525-529, May-Jun. 2010.

[31] S. Nagashima, T. Hasabe, A. Kamijo, Y. Yoshimoto, A. Hotta, H. Morita, H. Terada, M. Tanaka, K. Takahashi, and T. Suzuki, "Effect of oxygen plasma treatment on non-thrombogenicity of diamond-like carbon films," Diamond Relat. Mater., vol. 19, pp. 861-865, Jul.-Sep. 2010.

[32] R. N. Wenzel, "Resistance of solid surfaces to wetting by water," Ind. Eng. Chem., vol. 28, pp. 988-994, Aug. 1936.

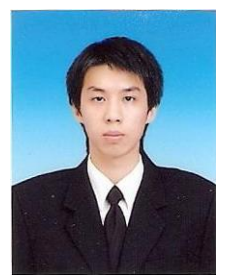

Chavin Jongwannasiri was born in Bangkok, Thailand. Mr. Jongwannasiri earned his B.Eng. and M.Eng. in Mechanical Engineering from King Mongkut's University of Technology Thonburi (KMUTT), Bangkok, Thailand in 2008 and 2010, respectively. He is currently a Ph.D. student of Systems Engineering major, Graduate school at Nippon Institute of Technology (NIT), Japan. His research major is in the field of thin film coatings and biomedical applications

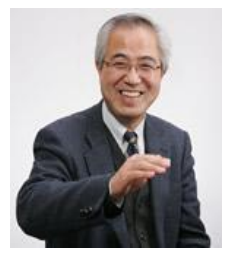

Shuichi Watanabe is the professor of Department of Innovative Systems Engineering at Nippon Institute of Technology (NIT), Japan. Prof. Dr. Watanabe earned his B.Eng. and M.Eng. in Metallurgical Engineering at Ibaraki University, Japan in 1977 and 1979, respectively. He also earned his Dr.Eng. in Mechanical Engineering at Nippon Institute of Technology, Japan. His research major includes surface engineering, thin film coatings, plasma process, materials engineering and tribology. He has worked in the field of thin film coatings for more than 20 years. He is members of The Surface Finishing Society of Japan, Japan New Diamond Forum, and Japanese Society of Tribologists. 